\title{
Maternal Preconception Stage
}

National Cancer Institute

\section{Source}

National Cancer Institute. Maternal Preconception Stage. NCI Thesaurus. Code C90340.

The stage in the life of a female during which she is attempting to get pregnant. 